Check for updates

Cite this: RSC Adv., 2017, 7, 38360

Received 14th June 2017

Accepted 30th July 2017

DOI: $10.1039 / c 7 r a 06644 a$

rsc.li/rsc-advances

\section{Self-healing polymeric materials for membrane separation: an example of a polybenzimidazole- based membrane for pervaporation dehydration on isopropanol aqueous solution}

\begin{abstract}
Chien-Ho Huang and Ying-Ling Liu (iD *
This study proposes a self-healing membrane for pervaporation separation, with a focus on in situ repairing damaged membranes within the separation module. The self-healing membrane is fabricated with a thermally-reversible crosslinked polybenzimidazole (PBI) based on a newly prepared furanfunctionalized $\mathrm{PBI}$ (PBI-FA) and a commercially-available bismaleimide (BMI) as raw materials. The thermally reversible crosslinked property and self-healing ability of the PBI-FA/BMI membrane have been evaluated using morphological and mechanical tests. The membrane demonstrates a high separation efficiency level (water concentration on the permeate side $\left(C_{\text {water }}>99.99\right.$ wt\%)) and moderate permeation flux $\left(117 \pm 11 \mathrm{~g} \mathrm{~m}^{-2} \mathrm{~h}^{-1}\right)$ for pervaporation dehydration with a $70 \mathrm{wt} \%$ isopropanol aqueous solution. Membrane damage caused by a knife incision engenders a loss of separation function. However, recovery of the separation function with a $C_{\text {water }}$ of approximately $94.27 \pm 0.14$ wt\% (selfhealing efficiency: 94\%) is achievable when the membrane was subjected to the self-healing process. Results from a 50 day long-term stability test indicate that self-healing efficiency could reach $97 \%$, with a recovered $C_{\text {water }}$ of approximately $96.83 \pm 0.24 \mathrm{wt} \%$. The self-healing process can prolong membrane life and reduce cost, effort, and wasted resources associated with total membrane replacement.
\end{abstract}

\section{Introduction}

Material failure during operation is a common complication that results in the loss of performance or function of devices. Repairs can be performed by replacing the failed components. However, device restoration may or may not be achievable, and replacing components can involve complicated and costly operations. Therefore, components constructed with selfhealing materials are highly attractive. In situ repairs of failed components can occur within the devices without requiring disassembly and reconstruction. Thus, self-healing polymeric materials have received substantial research attention regarding self-healing mechanisms and material designs. ${ }^{1-6}$ Studies have also considered the utilization of self-healing polymers in practical components and devices. To date, the most studied practical application of self-healing polymers is coating $^{7-11}$ because the materials and system designs require minimal complexity. Self-healing polymers have also been used to stabilize electrode materials in lithium batteries ${ }^{12,13}$ and as binding substrates for self-healing supercapacitors. ${ }^{14}$ Moreover, as membrane-based separations are energy-efficient, easily scaled-up, simple-to-operate, and flexible designs, self-healing

Department of Chemical Engineering, National Tsing Hua University, 30013 Hsinchu, Taiwan. E-mail: liuyl@mx.nthu.edu.tw; Fax: +886-3-5715408; Tel: +886-3-5711450 membranes have also been reported. In 2012 Tyagi et al. ${ }^{15}$ reported a porous membrane for filtration demonstrating a selfhealing ability, wherein membrane fragments could mend and recover separation performance. The self-healing mechanism was developed using pressure-driven molecular reassembly that maintained the circular geometry of the membrane. Pitsch et al. ${ }^{16}$ reported self-healing membranes for gas separation in 2012 with ionic liquids. Another example of a selfhealing cermet membrane for hydrogen separation was reported by Jeon et al. in 2013. ${ }^{17}$ Membrane damage caused by $\mathrm{H}_{2} \mathrm{~S}$ could be self-healed by converting $\mathrm{H}_{2} \mathrm{~S}$ to $\mathrm{SO}_{2}$ and $\mathrm{H}_{2}$. Recently, Fang et al. ${ }^{18}$ reported self-healing membranes for oilwater separation. Thermally-triggered self-healing on the membranes from damaged surface morphology and properties recovers its separation ability. On the other hand, healing agents-containing microcapsules ${ }^{19}$ and microvascular ${ }^{20}$ have been embedded in membranes to integrate the autonomous self-healing materials and the function of membrane separations.

Pervaporation process is highly effective for liquid-liquid separation especially for the heat sensitive materials and azeotrope solutions. ${ }^{21-24}$ Dense separation membranes for pervaporation frequently exhibit pinholes and microcracks produced during fabrication or long-term operation. Because the separation function depends primarily on membrane structure, the 
minor defects in the membranes could cause total performance failure of the pervaporation membrane. Moreover, most membrane devices are module structured. A single defective membrane that loses function within a module can consequently cause total module failure. As de-assembling the module to replace the defective membranes of the module is almost impossible, a current solution is total module replacement. Nevertheless, this action costs much and is not satisfactory. To overcome this problem, in situ repairing the damaged pervaporation membranes is highly expected. However, to the best of our knowledge, no studies have reported on self-healing membranes for pervaporation separation, since it is difficult to achieve because complete healing of damaged membrane portions is required to restore membrane separation ability.

We therefore delineate the first attempt in this work to develop self-healing membranes for pervaporation separation processes. Polybenzimidazole (PBI)-based membranes exhibited considerable potential for pervaporation dehydration on organic solvents, and were therefore utilized as matrix membranes in this work. ${ }^{24-29}$ The self-healing property was introduced to the PBI membrane by building a reversible crosslinked structure. ${ }^{4}$ PBI chains were first functionalized using furan groups and then crosslinked using a 4,4'-bismaleimidodiphenylmethane (BMI) compound through the furanmaleimide Diels-Alder (DA) reaction. ${ }^{4}$ The crosslinked structure of the resulting membrane based on the furan-maleimide DA adducts was thermally reversible. Self-healing of the membranes was triggered by thermal treatment that decrosslinked the membrane structure through a retro-DA reaction, mended the membrane pinholes and cracks with a chain motion, and reconstructed the crosslinked structure of the membrane through DA reactions. ${ }^{4}$ In practical operation, the damaged pervaporation modulus after long-term operation could be subjected to a self-healing process with a thermal treatment. A 99\% membrane efficiency recovery was observed during a pervaporation dehydration test with a $70 \mathrm{wt} \%$ IPA aqueous solution. ${ }^{30}$

\section{Experimental}

\section{Materials}

PBI was prepared in a laboratory in accordance with the conventional method reported in the literature. ${ }^{28}$ The obtained PBI had an inherent viscosity of $1.39 \mathrm{dL} \mathrm{g}^{-1}$ measured with a $N, N$-dimethylacetamide (DMAc) solution of PBI $\left(5.0 \mathrm{~g} \mathrm{~L}^{-1}\right)$ at $25{ }^{\circ} \mathrm{C}$. Commercially available 2-furoic acid (FA; Sigma-Aldrich) and BMI (Tokyo Chemical Co.) were used as received. Moreover, reagent grade solvents were applied as received.

\section{Instrumental characterization}

Fourier transform infrared (FTIR) measurements were performed with a PerkinElmer Spectrum Two instrument equipped with a thermal controller for measuring spectra at different temperatures. ${ }^{1} \mathrm{H}$ NMR spectra were recorded using a $500 \mathrm{MHz}$ NMR instrument (VARIAN, UNIYTINOVA-500 NMR), with dimethyl sulfoxide-d6 (DMSO- $\mathrm{d}_{6}$ ) as a solvent. Mechanical tests were performed on the membranes $(1 \mathrm{~cm} \times 3 \mathrm{~cm})$ by using an Instron 5540 tester at an elongation rate of $2 \mathrm{~cm} \mathrm{~min}^{-1}$. Dynamic mechanical analysis (DMA) was performed with an instrument (TA DMA-Q800) from Thermal Analysis Co. at a heating rate of $5{ }^{\circ} \mathrm{C} \mathrm{min}^{-1}$. Scanning electron microscopy (SEM) micrographs were recorded with a Hitachi S-4800 fieldemission SEM. A gas chromatography (Thermo Scientific Co., Model Trace 1300 GC) equipped with a Porapak Q column and a TCD detector (Thermo Scientific Co.) was used. A helium stream at a flow rate of $5 \mathrm{~mL} \mathrm{~min}{ }^{-1}$ was used as the carrier gas. The isopropanol concentrations of the permeates in pervaporation tests were determined. As the lower limit of the isopropanol concentration in the measurement is about $0.01 \mathrm{wt} \%$, the highest water concentration in the measurements is given as $>99.99 \mathrm{wt} \%$.

\section{Preparation of furan-functionalized PBI}

PBI $(1.20 \mathrm{~g})$ was dissolved in $50 \mathrm{~mL}$ DMAc at $80{ }^{\circ} \mathrm{C}$. After complete dissolution, FA $(0.87 \mathrm{~g}, 7.8 \mathrm{mmol})$ was added to the solution. The mixture was then reacted at $80{ }^{\circ} \mathrm{C}$ for $6 \mathrm{~h}$ in a nitrogen atmosphere. A crude product was obtained from precipitating the solution from excess methanol. The solid was collected using filtration, washed with methanol, and dried at $80^{\circ} \mathrm{C}(1.21 \mathrm{~g})$. The obtained furan-functionalized PBI was coded as PBI-FA.

\section{Preparation of crosslinked PBI membrane}

A 2 wt\% PBI-FA solution in dimethyl sulfoxide (DMSO) was prepared. After an addition of BMI (identical molar amounts from the maleimide and furan groups), the solution was filtered to remove insoluble impurity. The solution was cast on a glass substrate and then dried at $60{ }^{\circ} \mathrm{C}$ under vacuum for $48 \mathrm{~h}$. During the drying process, the membrane was crosslinked through the furan-maleimide DA reaction. Crosslinked PBI membranes (CR-PBI) with a thickness of approximately $25 \mu \mathrm{m}$ were taken for pervaporation tests.

\section{Pervaporation separation tests}

The membrane was subjected to pervaporation separation tests and was placed in a pervaporation cell between two stainless plates. The effective area of the membrane for separation is $7.0 \mathrm{~cm}^{2}$, which is similar to some cases reported in the literature. ${ }^{31-33}$ The membrane contacted with the feeding solution upstream, and the downstream (permeate side) pressure was reduced to approximately $667 \mathrm{~Pa}$. A steady state could typically be obtained after an operation of approximately $1-2 \mathrm{~h}$. Subsequently, materials that permeated the membrane were collected using a liquid nitrogen trap within a certain period. The collected sample was weighed and subjected to a composition analysis to obtain the membrane permeation flux and water concentration at the permeate side, respectively. The permeation flux $\left(J, \mathrm{~g} \mathrm{~m}^{-2} \mathrm{~h}^{-1}\right)$ of the membrane is obtained with,

$$
J=\frac{W}{A \times t}
$$




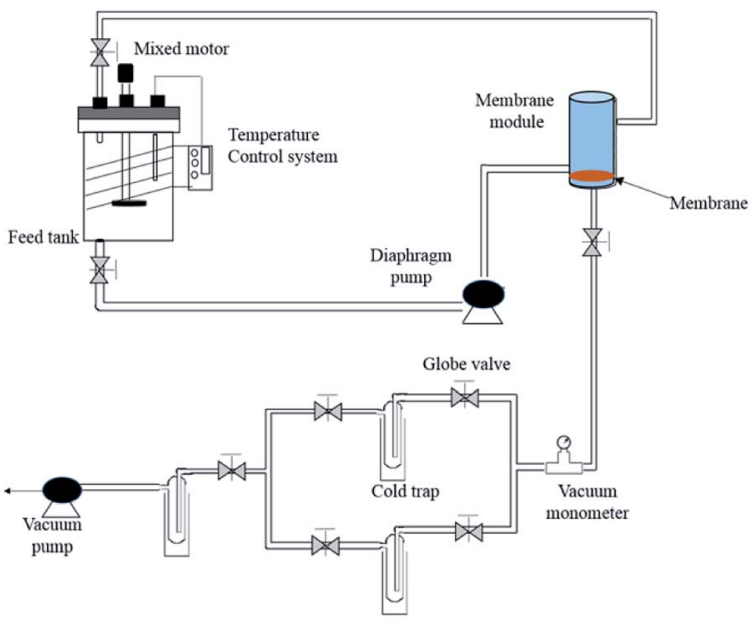

Fig. 1 Experimental setup for pervaporation separation tests.

where $W$ is the weight of liquid collected at the permeate side, $A$ is the effective area of the membrane, and $t$ is the period for collection of the permeate liquid. The experimental setup for pervaporation separation tests is shown in Fig. 1. The compositions of the feeding and permeate water/IPA mixtures were determined with a gas chromatography described above. The calibration curve method has been applied. The averaged values of the experimental data measured on 3-4 individual samples are reported with error bars.

\section{Results and discussion}

\section{Preparation of PBI-FA}

The self-healing and crosslinked PBI membranes were prepared with PBI-FA and BMI. Incorporation of furan groups into PBI chains was performed through the reaction between the secondary amine groups of PBI chains and the carboxylic acid group of the FA compound (Fig. 2). In an initial assessment, the furan group contents of the prepared PBI-FA samples could be tailored with the feeding ratios of the reactants of PBI and FA. However, a relatively small amount of the furan groups within PBI-FA produced a low crosslinking rate for the corresponding BMI-crosslinked membrane, which could cause poor pervaporation separation performance, operational stability, and efficiency of the self-healing ability. By contrast, the BMIcrosslinked membranes from PBI-FA samples possessing FA contents above $20 \mathrm{~mol} \%$ were too brittle for pervaporation tests. Therefore, a PBI-FA sample containing approximately $20 \mathrm{~mol} \%$ of FA substituents (PBI-FA-20) was selected for additional studies on self-healing pervaporation membranes.

A spectral characterization of the obtained sample (PBI-FA-20) is provided in Fig. 3. According to the FTIR measurement, PBIFA-20 exhibited the characteristic absorption of a PBI structure, including peaks of the $\mathrm{C}=\mathrm{N}$ group at $1623 \mathrm{~cm}^{-1}$ and the imidazole groups at 1536 and $1288 \mathrm{~cm}^{-1}$. The anchored furan groups were characterized by the absorption of $\mathrm{C}=\mathrm{C}$ and $\mathrm{C}-\mathrm{O}$ bonds at 1588 and $1021 \mathrm{~cm}^{-1}$, respectively. Moreover, FA exhibited a $\mathrm{C}=\mathrm{O}$ absorption of the $-\mathrm{C}(=\mathrm{O}) \mathrm{OH}$ group at
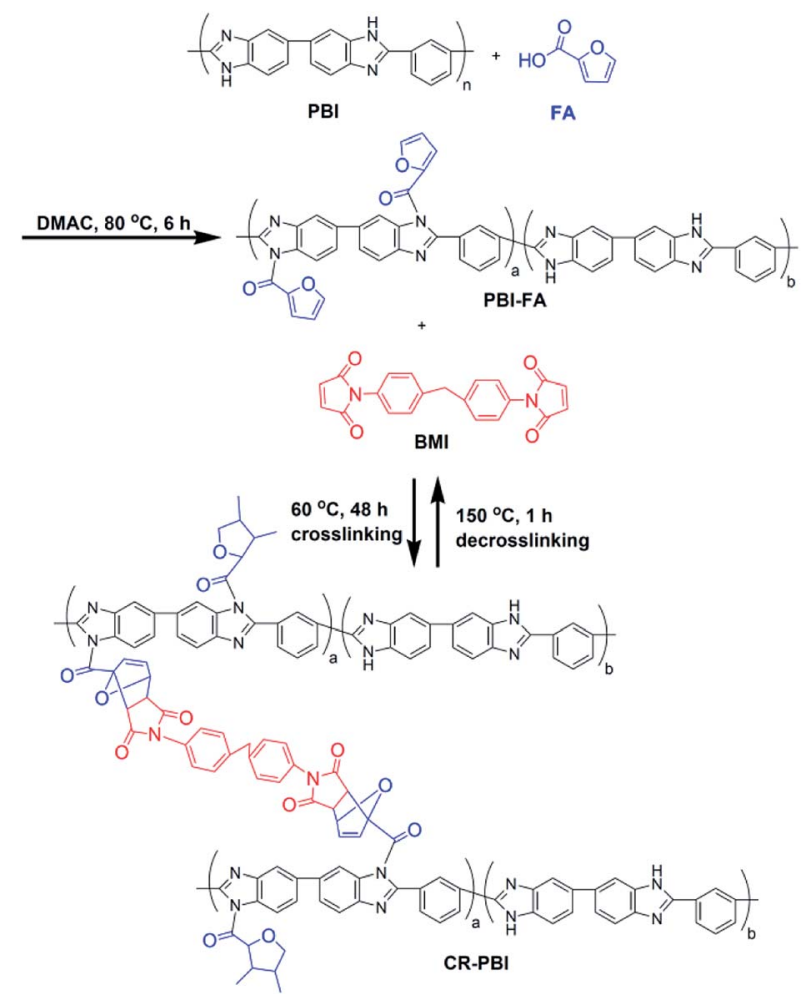

Fig. 2 Preparation of furan-functionalized polybenzimidazole polymer (PBI-FA) and the thermally-reversible crosslinking between PBIFA and a bismaleimide (BMI) crosslinking agent.

approximately $1690 \mathrm{~cm}^{-1}$. The $\mathrm{C}=\mathrm{O}$ absorption of PBI-FA-20 appeared at approximately $1730 \mathrm{~cm}^{-1}$. The shift in the $\mathrm{C}=\mathrm{O}$ group absorption indicated the formation of amide groups in PBI-FA-20 and the existence a reaction between PBI and FA. Further characterization was conducted using the ${ }^{1} \mathrm{H}$ NMR spectrum of PBI-FA-20, which exhibited resonance peaks corresponding to the aromatic protons of PBI at $\delta=7.6,7.8,8.0$, 8.3, and 9.1 ppm and the protons of furan rings at $\delta=6.6,7.1$,

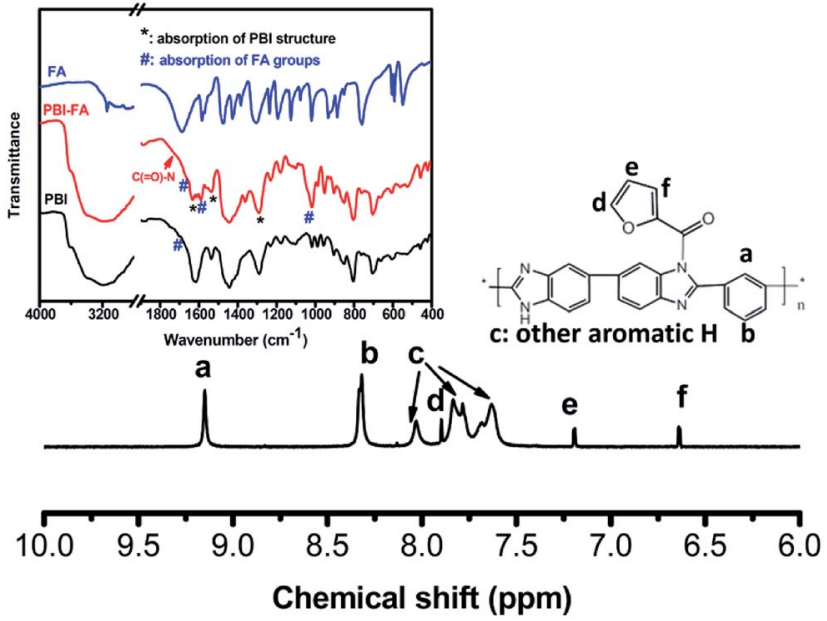

Fig. 3 Spectral characterization of furan-functionalized polybenzimidazole polymer with (a) FTIR and (b) ${ }^{1} \mathrm{H}$ NMR. 
and $7.9 \mathrm{ppm}$. A $-\mathrm{COOH}$ signal of FA at $\delta=13.0 \mathrm{ppm}$ was not observed within the PBI-FA-20 spectrum, indicating the existence of an amidation reaction as well as the formation of chemical bonds between the FA groups and the PBI chains. The degree of FA substitution for PBI-FA-20 obtained with the ${ }^{1} \mathrm{H}$ NMR spectrum (the peak area ratio of $\mathrm{f} / \mathrm{a}=0.44 / 2.60=0.169$ ) is about $17 \mathrm{~mol} \%$, which is similar to the theoretical value of $20 \mathrm{~mol} \%$.

\section{Fabrication and self-healing properties of crosslinked PBI membrane}

Regarding the fabrication of the crosslinked PBI membrane, BMI was used as a crosslinking agent for PBI-FA-20. The crosslinking reaction was first examined within a solution of PBI-FA-20 (2 wt\% in DMSO) and BMI. After being stored at $60{ }^{\circ} \mathrm{C}$ for $24 \mathrm{~h}$, the viscosity of the solution increased significantly. As this result is not observed with the neat PBI solution, the performance of Diels-Alder reaction between PBI-FA-20 and $\mathrm{BMI}$ and the formation of crosslinked PBI structure in the solution are demonstrated. ${ }^{34}$ As displayed in Fig. 4, the sample was then thermally treated at $150{ }^{\circ} \mathrm{C}$ to perform the retro-DAreaction on the DA adducts (the crosslinking points) to decrosslink the sample. ${ }^{35}$ Consequently, the viscosity of the solution decrease. The crosslinking and decrosslinking (changes between gel and solution state) of the sample was thermally reversible, and was repeated three times to demonstrate the thermal reversibility of the BMI-crosslinked PBI-FA-20 sample.

A PBI-based membrane was obtained by casting a freshly prepared solution of PBI-FA-20 and BMI on a plate substrate. The dried sample was then thermally treated at $60{ }^{\circ} \mathrm{C}$ for approximately $48 \mathrm{~h}$ to elicit the maleimide-furan DA reaction, which resulted in a CR-PBI. The thickness of the CR-PBI membrane was approximately $25 \mu \mathrm{m}$. Consequently, the crosslinked structure of the membrane, which was designed on the basis of the interconnected linkages of DA adducts, was thermally reversible. The crosslinked sample could be dissolved in DMSO at $150{ }^{\circ} \mathrm{C}$, and was insoluble in DMSO at $25{ }^{\circ} \mathrm{C}$, because at high temperatures, the crosslinked structure of the sample broke in the retro-DA reaction. This preliminary test

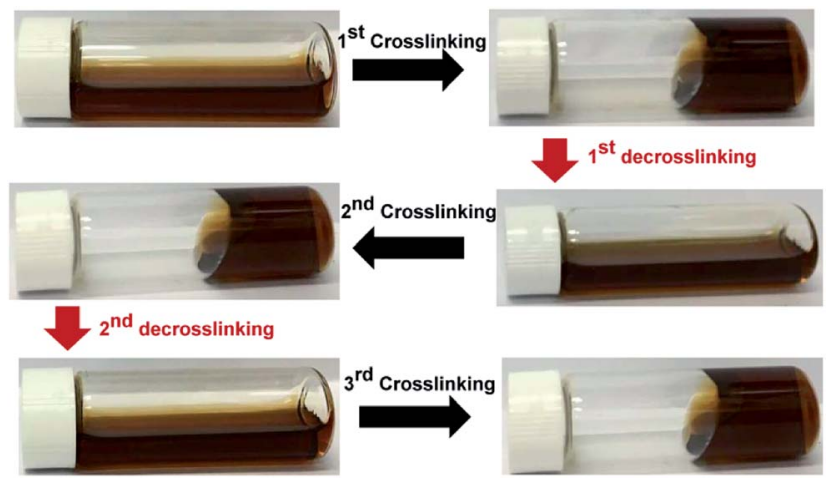

Fig. 4 Photographs showing the thermally-reversible crosslinking behavior of a solution of PBI-FA-20 and BMI. thus supports the thermally reversible crosslink characteristic of the CR-PBI membrane. These types of thermally reversible crosslinked polymers have been widely observed to demonstrate self-healing properties. ${ }^{\mathbf{4} 29,34}$ In Fig. 5, the self-healing property of the prepared CR-PBI membrane is examined. The left image at upper part shows that the membrane has been cut into two pieces. The completely separated membrane pieces have been put together and thermally treated at $150{ }^{\circ} \mathrm{C}$ for $1 \mathrm{~h}$ (triggering the retro-DA reaction to decrosslink the membrane) and at $60{ }^{\circ} \mathrm{C}$ for $48 \mathrm{~h}$ (performing the DA reaction to reconstruct the crosslinked structure)to trigger the self-healing process. The two piece samples link together, as shown in the right image, to demonstrate the high performance of self-healing ability. The self-healed sample is not so smooth due to the two pieces were partially stacked for examining the repairing ability. On the other hand, a piece of the CR-PBI membrane was partially cut with a knife to form a scar of approximately $19 \mu \mathrm{m}$. The scratched membrane in dry state (without solvent) was applied to the above-mentioned thermal treatment. The scar is also recovered after the thermally-triggered self-healing process. The relatively high temperature $\left(150{ }^{\circ} \mathrm{C}\right.$, which is higher than the usually temperature required for retro-DA reaction of furanmaleimide adducts) applied to the self-healing process is to enhance the PBI chain motion in the decrosslinked state, so as to smooth the cut-print effectively. The results support the heattriggered self-healing property of the CR-PBI membrane.

The self-healing property of the CR-PBI membrane was examined through mechanical tests, to further support to the performance of the self-healing behavior of the membranes. Fig. 6 shows the stress-strain curves of the membranes. The uncrosslinked PBI-FA-20 membrane was moderately tough, demonstrating an elongation at break of nearly $90 \%$. After being crosslinked with BMI, the CR-PBI membrane demonstrated an increase in maximum stress from 75 to $112 \mathrm{MPa}$ and a drop in the elongation at break from $90 \%$ to $40 \%$. The high maximum stress of CR-PBI membrane means its ability to resist the
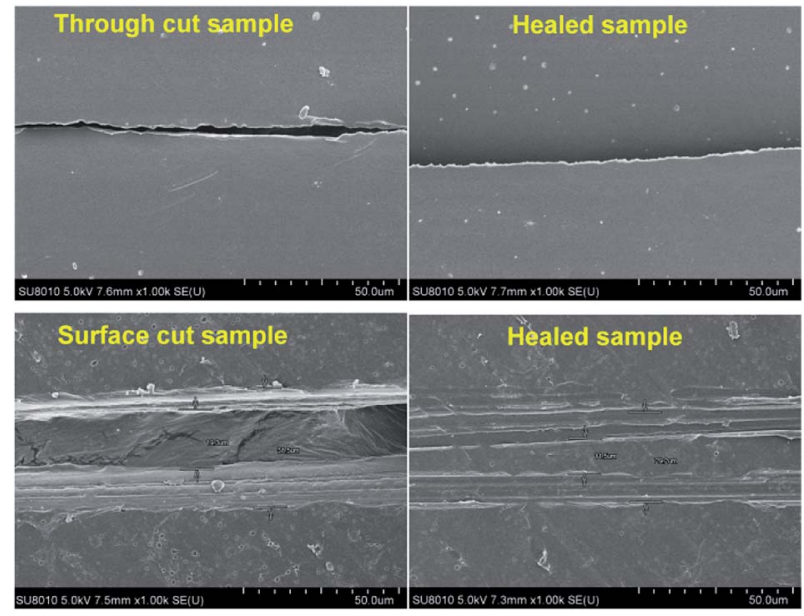

Fig. 5 SEM micrographs of the cut and thermally-induced self-healed samples of crosslinked PBI-FA-20 membrane (CR-PBI). The upper and lower part of micrographs shows the self-healing behavior on a fullycut sample and surface partially-cut sample, respectively. 


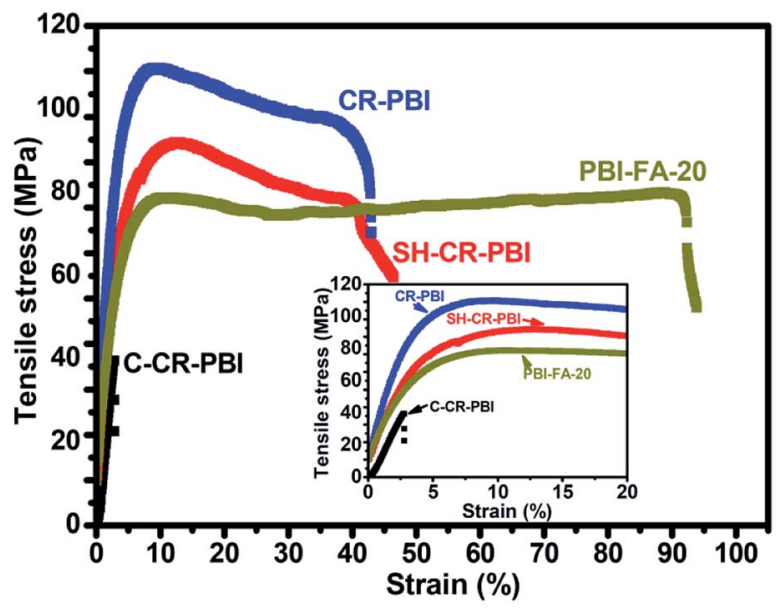

Fig. 6 Stress-strain curves recorded on the original PBI-FA-20 membrane, the corresponding crosslinked membrane (CR-PBI), the surface partially-cut sample (C-CR-PBI), and the self-healed sample (SH-CR-PBI thermally treated at $150{ }^{\circ} \mathrm{C}$ for $1 \mathrm{~h}$ and at $60^{\circ} \mathrm{C}$ for $48 \mathrm{~h}$ ).

applied forces (pressure difference between the feeding and permeate sides and force for fixing samples equipped in device) in pervaporation operation. It is noteworthy that the toughness of the crosslinked CR-PBI membrane (with an elongation at break of $40 \%$ ) warrants its resistance to break while being clamped in the pervaporation cells. Both the mechanical strength and toughness of the CR-PBI membrane are attractive for pervaporation separation.

To examine the self-healing property of the CR-PBI membrane, the membrane was tightly cut on the surface with a knife. The lacerated membrane (C-CR-PBI) broke at the cut position at an elongation of approximately $2 \%$ (maximum stress: $40 \mathrm{MPa}$ ) in the Instron test, and the scar became a mechanically weak position. The self-healing process was then applied to the C-CR-PBI membrane (thermal treatment at $150{ }^{\circ} \mathrm{C}$ for $1 \mathrm{~h}$ and $60^{\circ} \mathrm{C}$ for $48 \mathrm{~h}$ ). The self-healed membrane (SH-CR-PBI) exhibited a moderately favorable mechanical property (maximum stress: $92 \mathrm{MPa}$; elongation at break: $50 \%$ ) compared with the C-CR-PBI membrane. The self-healing efficiency calculated from the recovery ratio of the mechanical strength of the membrane was approximately $82 \%$. Mechanical property recovery and the aforementioned repairs of the morphological scar demonstrate the self-healing property of the CR-PBI membrane.

Moreover, the temperature-dependent mechanical property of the CR-PBI membrane is evaluated with a DMA (Fig. 7). The storage modulus does not show a significant change at temperatures below $125{ }^{\circ} \mathrm{C}$. The decrease in the storage modulus at temperatures between $125-200{ }^{\circ} \mathrm{C}$ might be attributed to the decrease in the crosslinking density of the membrane due to the occurrence of the retro-DA reaction. Nevertheless, as the pervaporation dehydration process is taken at temperature below $100{ }^{\circ} \mathrm{C}$, this temperaturedependent mechanical property of the CR-PBI membrane has not effects on its application for pervaporation dehydration.

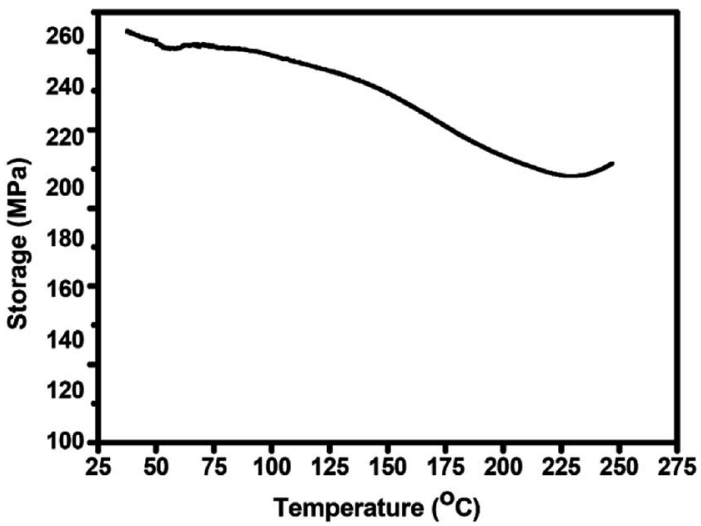

Fig. 7 DMA thermogram recorded on CR-PBI membrane.

\section{Self-healing CR-PBI membrane for pervaporation application}

The pervaporation performance of the self-healing CR-PBI membrane was recorded during a dehydration operation with a $70 \mathrm{wt} \%$ IPA aqueous solution. ${ }^{30}$ At $25{ }^{\circ} \mathrm{C}$, the PBI-FA-20 membrane exhibited a permeation flux of $186 \pm 5 \mathrm{~g} \mathrm{~m}^{-2} \mathrm{~h}^{-1}$ and a water concentration at the permeate side $\left(C_{\text {water }}\right)$ of about $98.11 \mathrm{wt} \%$, which are close to the values recorded with the pristine PBI membrane (Table 1). Crosslinking the PBI-FA-20 membrane with BMI resulted in a drop in the permeation flux $\left(117 \pm 11 \mathrm{~g} \mathrm{~m}^{-2} \mathrm{~h}^{-1}\right)$ and an increase in the separation ability with a $C_{\text {water }}$ value $>99.99 \mathrm{wt} \%$. This result is reasonable and similar to findings that have been widely reported for crosslinked polymer membranes. ${ }^{30}$ The CR-PBI membrane notably exhibited a $C_{\text {water }}$ of approximately $99.99 \mathrm{wt} \%$, indicating high selectivity to water permeation and stability for the feeding solution. A relatively low permeation flux of the CR-PBI membrane is commonly observed with crosslinked polymer membranes; this characteristic could be enhanced with hydrophilic surface modification, as reported in our previous studies. ${ }^{28,29}$

CR-PBI has been applied to pervaporation dehydration on isopropanol aqueous solutions in various concentrations and at different temperatures (Fig. 8). As isopropanol forms an azeotrope with water at about $87.9 \mathrm{wt} \%$ of isopropanol, the feeding solutions with isopropanol concentrations below $87.9 \mathrm{wt} \%$ are interested in so as to show the ability to perform the breakingazeotrope separation. The data shown in Fig. 8 demonstrates the ability of the membrane to enrich the isopropanol contents in the isopropanol aqueous solutions in a wide range of concentrations. While being operated at $25^{\circ} \mathrm{C}$, the permeation fluxes increase with increasing the water contents of the feeding solutions. This result is reasonable since a high water content of the feeding solution provides a high driving potential for water permeation. Moreover, for a feeding solution possessing high water content, the membrane swollen with water has less resistance to isopropanol permeation. Hence, the $C_{\text {water }}$ values show a slightly decrease with increasing the water contents of the feeding solutions. On the other hand, for a $70 \mathrm{wt} \%$ isopropanol aqueous solution, the permeation fluxes increase and the $C_{\text {water }}$ values decrease slightly with increasing the operation 
Table 1 Pervaporation performance of PBI-based self-healing membranes on a $70 \mathrm{wt} \%$ isopropanol aqueous solution at $25^{\circ} \mathrm{C}$

\begin{tabular}{lll}
\hline Membrane & $\begin{array}{l}\text { Permeation flux } \\
\left(\mathrm{g} \mathrm{m}^{-2} \mathrm{~h}^{-1}\right)\end{array}$ & $\begin{array}{l}\text { Water concentration } \\
\text { in permeate }(\mathrm{wt} \%)\end{array}$ \\
\hline PBI & $180 \pm 7$ & $97.58 \pm 0.50$ \\
$\begin{array}{l}\text { PBI-FA-20 } \\
\text { CR-PBI }\end{array}$ & $186 \pm 5$ & $98.11 \pm 0.39$ \\
$\begin{array}{l}\text { C-CR-PBI } \\
\text { (knife cut sample) }\end{array}$ & $117 \pm 11$ & $>99.99$ \\
$\begin{array}{l}\text { SH-CR-PBI } \\
\text { (healed C-CR-PBI) }\end{array}$ & $171 \pm 91 \pm 14$ & $73.27 \pm 1.55$ \\
$\begin{array}{l}\text { F-CR-PBI (failed CR-PBI } \\
\text { after long-term test) }\end{array}$ & $245 \pm 8$ & $94.27 \pm 0.14$ \\
$\begin{array}{l}\text { SH-F-CR-PBI } \\
\text { (healed F-CR-PBI) }\end{array}$ & $144 \pm 5$ & $83.78 \pm 0.26$ \\
& & $96.83 \pm 0.24$ \\
\end{tabular}

temperatures. The results are coincident to what widely reported to polymer-based membranes for pervaporation dehydration. Moreover, it is noteworthy that the errors recorded on the permeation fluxes are relatively high for the experiments on high-water-content feeding solutions and at high temperatures. This result could be reasonable since the membrane is less stable under the conditions of high water contents and high temperatures. Hence, the errors of the data shown in Table 1, which is recorded with $70 \mathrm{wt} \%$ isopropanol solutions and at $25{ }^{\circ} \mathrm{C}$, are relatively small.

The aforementioned lacerated C-CR-PBI was used to mimic a damaged membrane after a long-term pervaporation operation. The cut was carefully executed to prevent the formation of holes throughout the membrane. Therefore, the C-CR-PBI membrane could still perform pervaporation separation, exhibiting a permeation flux of $391 \pm 14 \mathrm{~g} \mathrm{~m}^{-2} \mathrm{~h}^{-1}$ and a $C_{\text {water }}$ of $73.27 \pm 1.55 \mathrm{wt} \%$. Compared with the pristine CR-PBI membrane (Table 1), the C-CR-PBI membrane exhibited similar separation behavior (decreased $C_{\text {water }}$ value and increased permeation flux) to a pervaporation membrane at the initial stage of losing its separation ability over long-term use. ${ }^{30}$ The drop in membrane separation performance could propagate substantially with operation time, engendering a complete loss of membrane separation ability, and resulting in complete failure of the membrane module. A solution to this problem is herein proposed. In our study, a C-CR-PBI membrane was subjected to a heat-triggered self-healing process $\left(150^{\circ} \mathrm{C}\right.$ for $1 \mathrm{~h}$ and $60{ }^{\circ} \mathrm{C}$ for $48 \mathrm{~h}$ ). Notably, SH-CR-PBI exhibited moderate recovery of pervaporation separation performance, with a permeation flux of $171 \pm 9 \mathrm{~g} \mathrm{~m}^{-2} \mathrm{~h}^{-1}$ and a $C_{\text {water }}$ of $94.27 \pm$ $0.14 \mathrm{wt} \%$ for a feeding stream of $70 \mathrm{wt} \%$ IPA aqueous solution. Compared to the $C_{\text {water }}$ value ( $>99.99 \mathrm{wt} \%$ ) recorded on the pristine CR-PBI membrane, the self-healing performance could be evaluated with the recovery of $C_{\text {water }}$ value. The $C_{\text {water-based }}$ recovery is calculated with the ratio of $C_{\text {water }}$ of self-healed membrane over $C_{\text {water }}$ of pristine CR-PBI membrane. The $C_{\text {water-based }}$ recovery of the membrane performance was approximately $94 \%$. The results provide preliminary support and confidence for the development of self-healing membranes for pervaporation dehydration processes.
A long-term operation was performed on the CR-PBI membrane. To conduct an aging test, the membrane was stored in a feeding solution and intermittently used for pervaporation experiments. Under these harsh conditions, the membrane partially lost its separation ability in a 50 day test with a $C_{\text {water }}$ of $83.78 \pm 0.26 \mathrm{wt} \%$, and a permeation flux of $245 \pm 8 \mathrm{~g} \mathrm{~m}^{-2} \mathrm{~h}^{-1}$ on pervaporation dehydration with a $70 \mathrm{wt} \%$ IPA aqueous solution. Similarly, the failed CR-PBI membrane (F-CR-PBI) was subjected to the self-healing process for membrane repair. The self-healed membrane exhibited a recovery of separation ability, with a $C_{\text {water }}$ of $96.83 \pm 0.24$ $\mathrm{wt} \%$, and a permeation flux of $144 \pm 5 \mathrm{~g} \mathrm{~m}^{-2} \mathrm{~h}^{-1}$ on pervaporation dehydration with a $70 \mathrm{wt} \%$ IPA aqueous solution. The $C_{\text {water-based recovery of the self-healed membrane performance }}$ was approximately $97 \%$.

The results discussed above indicate the ability and function of the self-healing membrane in practical pervaporation dehydration operations. Once the membrane module becomes failure after a long-term operation or caused with an accident harsh condition, in situ repairing the membrane to recover the separation ability of the membrane module, rather than abandoning the membrane modulus, is possible. This feature could prolong the lifetime of the membrane module significantly and
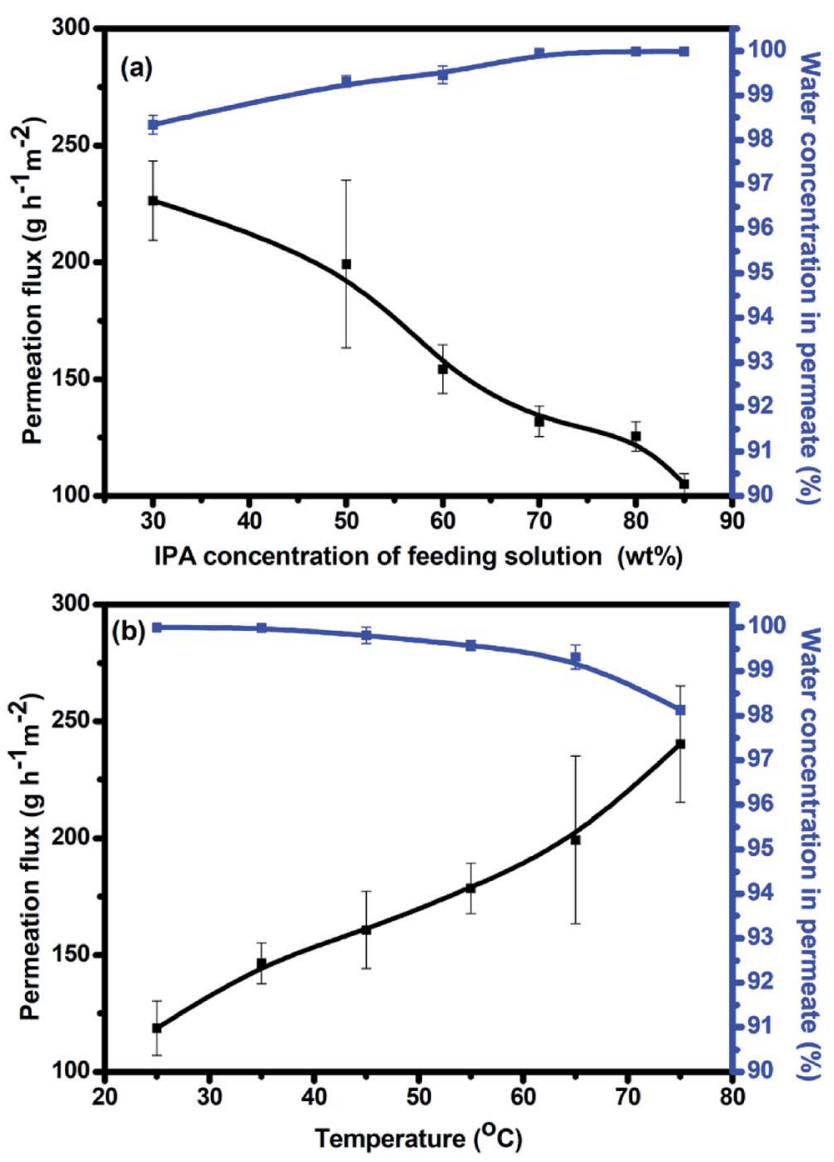

Fig. 8 Plots of pervaporation dehydration performance of CR-PBI membrane on (a) isopropanol aqueous solutions in different concentration at $25^{\circ} \mathrm{C}$ and (b) on a 70 wt\% IPA aqueous solution at various temperatures. 
save much money. The concept has been successfully demonstrated in this work. On the other hand, a self-standing dense membrane has been employed in the tests in this work. For composites membranes with selective layers of about $1 \mu \mathrm{m}$ in thickness, microcrack-induced failure on separation performance could occur commonly and frequently. Based on the selfhealing efficiency evaluated morphologically and mechanically and discussed above, the self-healing CR-PBI membrane could still be effective while being used as a thin selective layer of a composite membrane. Nevertheless, for the industrial application and scale-up issues, more examination on the selfhealing efficiency of the membranes inside a full size module are needs in further work.

\section{Conclusions}

This study reports a self-healing pervaporation membrane based on a thermally-reversible crosslinked PBI. Upon a thermal treatment process, the membrane exhibits substantial self-healing ability on morphological, mechanical, and pervaporation separation tests. Consequently, recovery of the separation performance of the membrane from mechanical and long-term operation damages is demonstrated with a recovery efficiency of about $97 \%$. Since a piece of damaged membrane could result in a total failure of the entire membrane module, the self-healing function of the pervaporation membrane is attractive and could effectively reduce the cost and effort required for total membrane replacement.

\section{Acknowledgements}

The authors thank the Ministry of Science and Technology (MOST) of Taiwan for the financial support on this work (Grant No. MOST102-221-E-007-135-MY3 and MOST-105-2218-E-155-007-). CHH thanks MOST of Taiwan for supports from the Research Program for Undergraduate Students (103-2815-C-007-035 E).

\section{Notes and references}

1 D. Y. Wu, S. Meure and D. Solomon, Prog. Polym. Sci., 2008, 33, 479-522.

2 S. D. Bergman and F. Wudl, J. Mater. Chem., 2008, 18, 41-62.

3 E. B. Murphy and F. Wudl, Prog. Polym. Sci., 2010, 35, 223251.

4 Y. L. Liu and T. W. Chuo, Polym. Chem., 2013, 4, 2194-2205.

5 V. K. Thakur and M. R. Kessler, Polymer, 2015, 69, 369-383.

6 X. K. D. Hillewaere and F. E. Du Prez, Prog. Polym. Sci., 2015, 40, 121-153.

7 V. Sauvant-Moynot, S. Gonzalez and J. Kittel, Prog. Org. Coat., 2008, 63, 307-315.

8 H. Wei, Y. Wang, J. Guo, N. Z. Shen, D. Jiang, X. Zhang, X. Yan, J. Zhu, Q. Wang, L. Shao, H. Lin, S. Wei and Z. Guo, J. Mater. Chem. A, 2015, 3, 469-480.

9 N. Y. Abu-Thabita and A. S. Hamdy, Surf. Coat. Technol., 2016, 303, 406-424.
10 K. Chen, S. Zhou and L. Wu, ACS Nano, 2016, 10, 1386-1394. 11 M. L. Zheludkevich and A. E. Hughes, Active Protective Coatings, 2016, vol. 233, pp. 157-199.

12 C. Wang, H. Wu, Z. Chen, M. T. McDowell, Y. Cui and Z. Bao, Nat. Chem., 2013, 5, 1042-1048.

13 R. Xu, I. Belharouak, J. C. M. Li, X. Zhang, I. Bloom and J. Bareño, Adv. Energy Mater., 2013, 3, 833-838.

14 H. Wang, B. Zhu, W. Jiang, Y. Yang, W. R. Leow, H. Wang and X. Chen, Adv. Mater., 2014, 26, 3638-3643.

15 P. Tyagi, A. Deratani, D. Bouyer, D. Cot, V. Gence, M. Barboiu, T. N. T. Phan, D. Bertin, D. Gigmes and D. Quemener, Angew. Chem., Int. Ed., 2012, 51, 7166-7170.

16 F. Pitsch, F. F. Krull, F. Agel, P. Schulz, P. Wasserscheid, T. Melin and M. Wessling, Adv. Mater., 2012, 24, 4306-4310.

17 S. Y. Jeon, M. B. Choi, B. Singh and S. J. Song, J. Membr. Sci., 2013, 428, 48-51.

18 W. Fang, L. Liu, T. Li, Z. Dang, C. Qiao, J. Xu and Y. Wang, Chem.-Eur. J., 2016, 22, 878-883.

19 S.-R. Kim, B. A. Getachew, S.-J. Park, O.-S. Kwon, W.-H. Ryu, A. D. Taylor, J. Bae and J.-H. Kim, Environ. Sci. Technol. Lett., 2016, 3, 216-221.

20 S.-R. Kim, B. A. Getachew and J.-H. Kim, J. Membr. Sci., 2017, 531, 94-102.

21 Y. K. Ong, G. M. Shi, N. L. Le, Y. P. Tang, J. Zuo, S. P. Nunes and T. S. Chung, Prog. Polym. Sci., 2016, 27, 1-31.

22 G. Jyoti, A. Keshav and J. Anandkumar, Journal of Engineering, 2015, 24.

23 M. Kárászová, M. Kacirková, K. Friess and P. Izák, Sep. Purif. Technol., 2014, 132, 93-101.

24 P. Luis, J. Degrève and B. Van der Bruggen, J. Membr. Sci., 2013, 429, 1-12.

25 G. M. Shi, Y. Wang and T. S. Chung, AIChE J., 2012, 58, 11331145.

26 Y. Wang, T. S. Chung and M. Gruender, J. Membr. Sci., 2012, 415-416, 486-495.

27 G. M. Shi, T. Yang and T. S. Chung, J. Membr. Sci., 2012, 415416, 577-586.

28 Y. J. Han, K. H. Wang, J. Y. Lai and Y. L. Liu, J. Membr. Sci., 2014, 463, 17-23.

29 Y. J. Han, W. C. Su, J. Y. Lai and Y. L. Liu, J. Membr. Sci., 2015, 475, 496-503.

30 Y. L. Liu, Y. H. Su, K. R. Lee and J. Y. Lai, J. Membr. Sci., 2005, 251, 233-238.

31 C. L. Li, C. Y. Tu, N. Inagaki, K. R. Lee and J. Y. Lai, J. Appl. Polym. Sci., 2006, 102, 909-915.

32 H. Zhou, L. Lv, G. Liu, W. Jin and W. Xing, J. Membr. Sci., 2014, 471, 47-55.

33 Z. W. Song, J. M. Zhu and L. Y. Jiang, J. Membr. Sci., 2014, 472, 77-90.

34 T. W. Chuo and Y. L. Liu, Compos. Sci. Technol., 2015, 118, 236-243.

35 Y. L. Liu, C. Y. Hsieh and Y. W. Chen, Polymer, 2006, 47, 2581-2586. 